\title{
Politização indígena e crise da política indigenista no Brasil ${ }^{1}$
}

\author{
Priscila Faulhaber-Barbosa
}

DOI - 10.25160/v5i2.ga.7

O presente trabalho visa contribuir para o entendimento da imagem do índio hoje no Brasil, a partir da análise histórica da relação dos índios com o mundo dos brancos. Trata-se assim relevante considerar analiticamente como o contato interétnico, os movimentos e as organizações indígenas foram pensados na história da antropologia brasileira quando estudos relevantes neste campo passam a ser elaborados para a abordagem da participação dos índios em movimentos de esfera local e nacional. Como ponto nodal da reflexão focalizo, além do contato interétnico, a legislação formulada com base na tutela, considerando a definição de prática tutelar, entendendo-a enquanto capilaridade do exercício do poder de estado que se consubstancia no regime de dominação aos quais os índios vêm sendo historicamente submetidos, o que justifica deste modo voltar o estudo ao exame da significação do contato e das fronteiras étnicas.

\section{Uma abordagem de história da antropologia}

A definição dos parâmetros antropológicos como disciplina científica data do início do século XX, como a fundação das "escolas" francesa, inglesa e americana de antropologia. Desde então, os seus paradigmas, noções e métodos relacionados com as culturas indígenas estiveram associados a formulações éticas que servem como parâmetro para aqueles que recebem formação antropológica.

O conhecimento antropológico busca uma alternativa a esquemas científicos que - em nome da objetivação cognoscente - têm formulado uma gradação evolutiva entre "préciência" e "ciência desenvolvida". Isto iria implicar um determinismo, como se o único caminho válido fosse o caminho seguido pela ciência ocidental. Desde Boas, a antropologia

\footnotetext{
${ }^{1}$ Este artigo já estava em elaboração quando iniciei a interação com estudantes indígenas (no feminino) em projeto apoiado pelo IPEAT da Universidade de Toulouse Jean- Jaurés (cátedra América Latina). Agradeço às que prestaram depoimento neste contexto, cujo testemunho contribuiu para a reflexão sobre temas aqui examinados. Sou grata igualmente ao parecer anônimo que criticou a versão inicial, orientando a recortar o enfoque do presente texto.
}

RRASILIANA- Journal for Brazilian Studies. Vol. 5, n.2 (July, 2017). ISSN 2245-4373. 
aponta que do ponto de vista antropológico a suposição da unidade psíquica da humanidade não é demonstrável (Spiro, 1992:127).

Em Dilthey (1880-1890), as ciências humanas particulares são diferenciadas das ciências naturais e distinguidas entre si como fatores da realidade socio-histórica, com a dissolução da atitude metafísica diante da realidade. Para Dilthey, as formas de pensamento podem ser examinadas mediante julgamento, conceituação, inferência, dentro da esfera das operações lógicas. Posteriormente, a hermenêutica é aplicada à psicanálise por Freud (Lacan, 1988, pag 9-20), na análise do inconsciente individual, e à etnologia.

Os efeitos perversos da postura hermenêutica em antropologia levam ao interpretativismo (Cardoso de Oliveira, 1998:68). Uma volta à esfera da intersubjetividade afigura-se como um antídoto contra tais efeitos, no contrapeso entre procedimentos compreensivos e interpretativos, em um processo reflexivo com o qual a antropologia assume uma posição de crítica cultural (Marcus e Fisher, 1986), na qual a experimentação etnográfica ocupa um lugar central, que serve como base para a construção analítica. Volta-se aqui à hermenêutica à análise dos discursos sobre o índio, considerando este último como sujeito que intervêm nos campos discursivos e nas práticas sociais.

A perplexidade diante das inevitáveis transformações sócio-históricas e de toda sorte de impactos que atingem os povos indígenas impõe uma complementaridade entre a prática antropológica e a perspectiva ética, em constante redefinição. A constatação permanente da crise e do caráter provisório dos parâmetros morais "não transfere a premência dos problemas" (Bornheim, 1999:257). Os questionamentos sociais e políticos, que se colocam a partir dessa eticidade, não podem deixar de ser equacionados enquanto tais.

\section{A antropologia brasileira, as comunidades e as culturas indígenas.}

Tem sido apontado, por vários autores, que o estudo da cultura indígena não pode ser dissociado das situações sociais de cada comunidade indígena. Comunidade indígena se define a partir da consciência, pelos membros desta comunidade, "de sua continuidade histórica com as sociedades pré-colombianas" (Carneiro da Cunha, 1987:26). Sendo assim, as comunidades "em contato", integradas ou em diferentes modalidades de integração, aos olhos da legislação indigenista no Brasil, em termos jurídicos não deixam de ser consideradas indígenas, uma vez que os seus membros se considerem indígenas e sejam considerados enquanto tais. Esta definição vai contra critérios evolucionistas que suponham graus de

RRASILIANA- Journal for Brazilian Studies. Vol. 5, n.2 (July, 2017). ISSN 2245-4373. 
integração, em que os índios progressivamente irão perder sua cultura tradicional, uma vez que se integrem à sociedade nacional.

Considero relevante a crítica da mitificação embutida na noção de "aculturação" dos índios, e por consequência da ideia que os índios integrados perdem sua cultura original, como se fosse um recipiente cujo conteúdo se esvaziaria conforme se cumprissem as etapas de um processo de integração considerado natural e inevitável. Mesmo antes da chegada do homem branco os diferentes povos indígenas, que interagiam entre si por meio de relações pacíficas, conflituosas, ou mesmo guerras intertribais, sofriam influências mútuas, concretizavam empréstimos culturais e transformavam-se uns aos outros, reinterpretando formas culturais não autóctones dentro de seus próprios parâmetros. A cultura abrange diferentes fatores, sobretudo quando se trata de situações de contato entre povos etnicamente diferenciados. A noção de aculturação é passível de crítica uma vez que os grupos étnicos diferenciados persistem apesar das variações culturais, do contato e da interdependência étnica (Barth, 200:26).

As teorias do contato relativizam definições propostas com base na crítica da definição de cultura por Eduardo Galvão. Este autor apresenta importante contribuição ao reformular os estudos de áreas culturais americanos a partir de análises feitas no Brasil com base em pesquisas etnográficas, considerando o contato interétnico como um fator relevante (Galvão, 1979:194). A partir de estudos entre vários grupos indígenas, este autor analisa o "encontro de sociedades" (sociedades nacionais e sociedades indígenas) como um processo de mudança cultural. Para Galvão, o processo de destribalização e assimilação dificilmente se completará, uma vez que sempre haverão aqueles índios que "tentarão manter vivas as línguas, as tradições e o sentido de comunidade" (Galvão, 1979:144). Mas a sua visão de mudança cultural não é satisfatória.

Cardoso de Oliveira cunha a noção de "fricção interétnica" (Cardoso de Oliveira, 1996) visando uma alternativa à explicação das mudanças culturais em termos de "aculturação" tal como proposto pela antropologia cultural americana. Não se trata mais de uma volta à ideia das sociedades indígenas intocadas e da tarefa da reconstrução cabal de suas culturas originais (Redfield, Linton e Herskovitz, 1936). O trabalho do antropólogo consiste em analisar como, na situação de contato, são constituídos estereótipos sobre os índios - os Tikuna, no estudo de Cardoso de Oliveira - sem desconsiderar enunciados produzidos nas falas destes índios como inseridos em campos semânticos formados a partir de simbolizações específicas ( Cardoso de Oliveira 1972: 32).

RRASILIANA- Journal for Brazilian Studies. Vol. 5, n.2 (July, 2017). ISSN 2245-4373.

(c) (1) (3) 393 
Cabe, neste sentido, a discussão conceitual de definições com o "regime tutelar" na análise das situações sociais enquanto situações históricas desenvolvidas por João Pacheco Oliveira; Trata-se de identificar como a dinâmica da dominação é reinterpretada pelos Tikuna em seus próprios termos (Oliveira, 1988:105).

Pacheco de Oliveira considera o "regime tutelar" (Oliveira, 2015) enquanto um sistema que implica a sujeição dos índios seja nos sistemas de clientela manejados pelos comerciantes, seja pela tutela que os inferioriza considerando-os "relativamente incapazes". Já Antonio Carlos de Souza Lima analisa historicamente o "poder tutelar"(Lima, 1995) considerando o exercício de formas históricas de dominação na criação do Serviço de Proteção aos Índios. Reformula esta concepção para examinar como a política indigenista da FUNAI articula-se enquanto poder de estado no exercício da tutela. Enfatizo aqui as práticas tutelares como mecanismos de poder que são exercidos capilarmente de modo que o habitus tutelar é interiorizado pelos próprios índios (Faulhaber, 2003).

Na atualização de sua contribuição, Cardoso de Oliveira (1996) reconhece que o entendimento da estrutura social - que enfatizou com sua noção de "fricção interétnica privilegia o aspecto estrutural, sem estabelecer a devida crítica a noções do senso comum indigenista envolvendo a assimilação e a integração dos índios à comunhão nacional. Tal como previsto na legislação especial, o Estatuto do Índio, Lei 6001 de 1973 vale-se a figura da tutela articulada como à prerrogativa positivista da "integração" do índio à comunhão nacional, que leva à exclusão dos direitos especiais daqueles que sejam considerados "integrados".

A sistematização da abordagem da antropologia histórica advogada por Pacheco de Oliveira (Oliveira, 1999, 2005) focaliza a sujeição dos indos pelos patrões ou a sua inferiorização pela FUNAI através da tutela indigenista como processos de dominação em situações históricas determinadas considerando acontecimentos históricos em pesquisas empíricas. Novos trabalhos consideram processos políticos e históricos em situações concretas de fronteira (Faulhaber, 1998, 1999, 2012, Gárcez, 2015).

\section{Política e legislação indigenista: do SPI à FUNAI}

Para o exame do campo de forças em que surgiu a nova face indígena, cabe remontar à história da política indigenista. 
O Serviço de Proteção aos Índios (SPI) data de 1910 (Lima 1995), criado por militares positivistas juntamente com a construção de linhas telegráficas nas fronteiras com o discurso de proteção e integração dos índios conquistaram territórios e submeteram a força de trabalho indígena.

Nos processos de colonização, o contato interétnico estabeleceu-se em situações históricas de submissão através de relações clientelísticas como expressões locais cadeia de dominação e manejadas por comerciantes e proprietários dos meios de dominação. Não obstante, o SPI como instituição de escala federal implicava mecanismos de reconhecimento de "áreas indígenas" e de direitos básicos de cidadania pelos índios que nelas habitavam.

Com dificuldades de acesso às áreas remotas pelos agentes do SPI, a garantia dos direitos de ocupação destas terras era conquistada com a participação dos índios como ocorreu com os Miranha das "aldeias" do Miratu e da Méria (Estado do Amazonas) que se entrincheiravam para garantir colocar os marcos e afirmar seus limites territoriais diante dos comerciantes locais. (Faulhaber, 1987). Os Miranha haviam migrado para o Brasil pelo Caquetá colombiano fugindo dos exploradores do caucho na primeira década do século XX. O reconhecimento de suas terras no Brasil ocorreu na gestão de Bento Martins Pereira de Lemos (1916 a 1932). Para este, a tutela orfanológica prescrita pelo código civil disfarçava o escravismo aos índios (Freire, 1990. 2007). Isidoro Sampaio, Inspetor de Índios na Primeira Delegacia Regional que atendia a Amazônia Ocidental, sofria pressões por parte dos senhores locais contrários às estratégias do SPI que agiam como "senhores feudais" (Sampaio,1928). Reconhecendo áreas Miranha no Brasil em Méria em 1928 e Miratu em 1929, por meio da intervenção do SPI, autorreputada como "nacionalizadora" e intervindo assim como "dispositivos do processo civilizador"(Faulhaber, 2012:419). Neutralizavam assim as suspeitas de que o Brasil teria participado do comércio clandestino de indígenas, prática corrente em áreas de fronteiras com Colômbia e Peru (Faulhaber, 2005).

Em inventário com base nos arquivos do SPI em 1957 a população indígena brasileira foi estimada entre 68100 e 97000 indivíduos englobando 143 etnias (Ribeiro, 1970:258) sendo que no entanto só se dispunham informações sistemáticas sobre 110 delas. Contabilizaram-se 21 povos isolados.

No Censo de 2010 realizado pelo Instituto Brasileiro de Geografia e Estatística (Oliveira, 2015), foram computados 896900 índios, compreendendo 305 grupos étnicos, entre os quais os mais numerosos, os Guarany e os Tikuna, com população de 40.000. Estavam demarcadas 505 terras indígenas, ocupando $12.5 \%$ do território brasileiro

RRASILIANA- Journal for Brazilian Studies. Vol. 5, n.2 (July, 2017). ISSN 2245-4373. 
A Fundação Nacional do Índio (FUNAI) foi criada 1967 durante o regime militar, no quadro de políticas de integração nacional subordinada ao Ministério do Interior. Em meados dos anos 1970 o Estatuto do Índio (Lei 6001 1973) instaura diferentes "mecanismos de expropriação legal" (Albert 1997 :179). Em resumo:

1- Atividades consideradas como a serviço do desenvolvimento e da Segurança Nacional tais como obras públicas, empreendimentos agrícolas ou empresas de exploração mineral justificam deslocamentos forçados de aldeias.

2 - O quadro jurídico e retórico "protecionista" erige a concepção de tutela com base no estatuto jurídico de capacidade relativa. Esta implica a condição de minoridade do índio imbricada na formulação de identidade indígena genérica e configura o discurso indigenista nacional que remete ao Marechal Rondon, o peso político da Igreja Católica e os fundos filantrópicos internacionais. Assumida pelo Estado, esta implica a obrigatoriedade de assistência jurídica, sanitária, econômica e educacional por meio da administração da FUNAI. Os índios considerados "emancipados" são vistos como integrados individual ou coletivamente e perdem o direito à proteção.

3 - Como a legislação confere a propriedade do solo e do subsolo das terras nacionais à União resta aos índios somente a posse de seus territórios. Este regime territorial atribui aos índios a ocupação e usufruto exclusivo de espaços coletivos específicos sob a forma de terras reservadas, parques, colônias agrícolas, e territórios federais. Segundo o Estatuto do Índio, cabe ao Estado conservar a propriedade, definir os limites e supostamente garantir a integridade. Cobiçados por indivíduos grupos e corporações visualizando a exploração de seus recursos, apesar do processo jurídico de reconhecimento, estes têm sido de fato sujeitos a todo o tipo de intrusão com conivência ou não de agentes indigenistas.

\section{Movimentos indigenistas e reivindicação de protagonismo indígena}

A mobilização contra a emancipação indígena foi lançada em 1976, como resposta à proposta da FUNAI, que consubstanciava uma política deliberada de restrição ao reconhecimento da etnicidade de índios considerados destribalizados. Dela participavam juristas progressistas e a entidades de apoio ao índio (comissões pró- índio /CPI e sedes locais da Associação 
Nacional de Apoio ao Índio/ANAI) em diferentes cidades do Brasil (São Paulo, Bahia, Manaus, Rio de Janeiro), paralelamente a movimentos da sociedade civil pela democratização do país em que se fortalecia a pressão da opinião pública pela quebra do autoritarismo militar, por liberdades democráticas e pela anistia dos presos políticos. A grande repercussão nacional e internacional das falhas do discurso indigenista e da expropriação em curso acarretaram o recuo dos agentes que manejavam a política indigenista oficial, que colocaram o projeto de emancipação em suspenso.

A emergência do movimento indígena como um ator reconhecido nacional e internacionalmente foi incentivada com a formação de assembleias indígenas, apoiadas por comunidades eclesiais de base e pelo Conselho Indigenista Missionário, bem como por pesquisadores e militantes indigenistas que contribuíram para promover a criação de organizações indígenas nacionais e locais. Entre as primeiras organizações que surgiram no final dos anos pode ser citada a União das Nações Indígenas (UNIND e logo a seguir UNI), que surgiu paralelamente a uma reunião da Comissão Pró Indio de São Paulo quando estiveram presentes representantes indígenas locais que constituíram diretoria (Presidente: Marcos Terena, Tesoureiro: Álvaro Tucano e Secretário: Lino MIranha) tendo em vista a organizar o primeiro encontro da UNI que ocorreu em Brasília em 1981². Destaca-se entre as organizações locais independentes o Conselho Geral da Tribo Ticuna, criado em assembleia indígena em $1981^{3}$. A legitimidade destas mobilizações era colocada em cheque pelos setores anti-indígenas, tendo próprio termo "nações indígenas" sido considerado subversivo durante o regime militar (Ramos, 2000; Oliveira, 2014).

\footnotetext{
${ }^{2}$ Esta reunião teve apoio das ANAIs e das CPIs, bem como da Associação Brasileira de Antropologia, que atuava informalmente através de antropólogos interessados. Atuando com Segunda Secret[aria da ABA regional de Brasília e membro da Comissão de Movimentos Sociais desta Associação, participei das atividades de apoio a este evento. O mesmo foi, contudo, conduzido pelos próprios índios.
}

${ }^{3}$ O Conselho Geral da Tribo Ticuna (CGTT) foi formalmente fundado no ano seguinte, em 1982, com a figura do coordenador geral, eleito por assembleia conduzidas por capitães, como são chamados os chefes de cada aldeia. Posteriormente, foram criadas: a Organização dos Professores Ticuna Bilíngües (OGPTB), fundada em 1986 por professores Tikuna; a Organização dos Monitores de Saúde do Povo Ticuna (OMSPT); e a Organização de Saúde do Povo Ticuna do Alto Solimões (OSPTAS), em 1990 Em1986, foi criado o Centro Magüta - Centro de Documentação e Pesquisa do Alto Solimões,com o auxílio de pesquisadores da UFRJ que atuavam na área desde os anos 1970. A demarcação, em 1993 foi fruto deste movimento organizativo, garantindo aos Tikuna cerca de um milhão de hectares de terras no Estado do Amazonas. O Centro Magüta realizou ainda trabalhos nas áreas de saúde e desenvolvimento. Entre 1996 e 1997 o Centro deixou de existir e na sua sede passou a funcionar o CGTT. Posteriormente foram formadas outras organizações, como a AMIT e a AMATU estas duas últimas formadas por mulheres para lograr autonomia na comercialização de bens artesanais por elas produzidos. URL https://pib.socioambiental.org/pt/povo/ticuna/1344

RRASILIANA- Journal for Brazilian Studies. Vol. 5, n.2 (July, 2017). ISSN 2245-4373. 
Os movimentos indígenas posicionavam-se como resposta aos programas de desenvolvimento do regime militar, que apesar de nacionalistas, não consideravam a questão indígena. A principal palavra de ordem naquele momento era a urgência da demarcação das terras indígenas. No entanto, ao mesmo tempo em que suas lideranças tivessem reconhecimento nacional e internacional tendo a imagem do índio genérico grande apelo midiático, os movimentos nas esferas locais atravessadas por sistemas clientelísticos e paternalisatas eram incipientes.

A heterogeneidade dos discursos sobre o índio passou a ser posta em evidência com a emergência do movimento indígena como um ator expressivo no cenário político nacional a partir dos anos oitenta, em campos complexos de influências A representatividade das lideranças era questionada em suas bases. Os índios de comunidades remotas reclamavam da falta de representatividade dos que ocupavam funções de dirigentes nas organizações indígenas a nível local, regional ou nacional. (Faulhaber, 1983). Caracterizava-se a situação de crise do indigenismo (Cardoso de Oliveira 1988) já que embora estivesse claro que entidades e agências da sociedade civil não podiam falar em nome do índio, a organização indígena tampouco era reconhecida em seu protagonismo.

Registraram-se, todavia, líderes indígenas com posições firmes contra o etnocídio e a interferência dos brancos em seu processo organizativo, como Marçal Tupã i, assassinado em dezembro de 1983, Mário Juruna que participou do Tribuna Russel e foi eleito deputado Federal e Raoni Metuktire, legendário por seus posicionamentos na reivindicação de demarcação de terras e reconhecimento dos interesses indígenas Estes índios mostravam em suas ações que longe de ser heróis românticos (Faulhaber, 1986, 1998)., espelhavam sociedades indígenas atravessadas por intensos conflitos mas sem deixar de ser elas mesmas na luta pela auto determinação.

No contexto da Nova República, com a quebra da ditadura militar, a FUNAI foi deslocada para o âmbito do Ministério da Justiça, no reconhecimento que a questão indígena era emblemática no que toca ao desrespeito aos crimes contra a humanidade. A Convenção 169 da OIT de 1989 veio a reconhecer a urgente necessidade de se respeitar e promover os direitos dos povos indígenas no mundo, especialmente os direitos a suas terras, territórios e recursos. A declaração da ONU quanto aos direitos dos povos originários foi aprovada anos depois, em 2007.

Os índios e entidades indigenistas tiveram papel ativo no processo constitucional, destacando-se na movimentação da sociedade civil pela participação na Assembleia Nacional 
Constituinte, que veio a se corporificar em 1987, resultando na promulgação da nova Constituição em 1988.

A Carta Magna criou condições para institucionalizar a participação indígena. No entanto, os mecanismos apresentavam fissuras mostrando aporias na chamada crise do indigenismo. Oliveira diferencia movimentos, assembleia, redes e líderes. Na tipologia proposta por este autor (2015), cabe distinguir as seguintes posições: 1.Funcionários indígenas que trabalham nas instituições de Estado no Brasil. 2.Organizações, formalizadas juridicamente em acordo com a Constituição de 1988 e segundo parâmetros da Sociedade Nacional. 3.Movimentos indígenas, que não estão diretamente condicionados pela institucionalização jurídica.

Paralelamente ao enfraquecimento da chamada UNI, multiplicou-se o número de organizações indígenas que surgiam dinamicamente, em resposta a demandas de movimentos de base. Em 1989 foi fundada a COIAB(coordenação de organizações indígenas da Bacia Amazônica), reunindo 75 organizações membro (dos estados do Amazonas, Acre, Amapá, Maranhão, Mato Grosso, Pará, Rondônia, Roraima), englobando associações locais, estaduais, federações regionais e organização de mulheres, de professores e estudantes indígenas.

Os movimentos e organizações indígenas vieram a buscar compatibilização sob a esfera do Comitê de articulação das organizações indígenas no Brasil (CAPOIB. Criado em 1992. A chamada Articulação dos povos indígenas no Brasil (APIB), formalizada em 2002. (URL): http://www.apib.org.br/institucional/ 99. O número de organizações cresceu para 486 (Bicalho, 2010).

A crise de representatividade tem se manifestado em muitos níveis, sendo que frequentes vezes os índios que vivem em comunidades interioranas não se sentem representados pelos que ocupam posições dirigentes nas organizações indígenas de âmbito local, regional ou nacional. Estratégia alternativa de organização foi criada em 2005 através da Articulação dos Povos Indígenas do Brasil (APIB) ${ }^{4}$

As posições ocupadas pelos atores indígenas envolvem estratégias que são elaboradas em diferentes campos. Os movimentos e organizações convergem no sentido da consolidação do poder da sociedade civil, compatíveis com projetos e estratégias que visualizem a cidadania indígena construída em termos de territórios étnicos. Não estão

\footnotetext{
${ }^{4}$ Fonte(URL): http://www.apib.org.br/institucional/
} 
contidos pelas mesmas limitações institucionais que condicionam a esfera de atuação dos funcionários indígenas Para o movimento indígena, o que importa é o reconhecimento dos direitos coletivos; Este posicionamento implica a manutenção de uma oposição ao Estado, estabelecendo alianças com outros setores igualmente excluídos. No caso das organizações indígenas, a prioridade é dada à gestão territorial de acordo com demandas públicas de conservação ambiental e desenvolvimento (Oliveira, 2015). O campo indígena como um todo apresenta uma combinação de todos estes atores, que muitas vezes transitam dos movimentos para as organizações e destas para a esfera burocrática sendo registradas colaborações e retorno ao meio de origem e aos movimentos de base. Um fato novo que se apresenta, com os movimentos de professores e a formação curricular indígena são os estudantes indígenas em universidades, cursando pós-graduação, obtendo títulos de mestrado e doutorado, que passam a ver todo este processo reflexivamente.

\section{Heterogeneidade das formulações jurídicas sobre os índios e práticas tutelares}

Para esclarecer aspectos da situação dos índios no Brasil hoje, farei a seguir uma breve exposição sobre os textos jurídicos atualmente operantes referentes ao índio, considerando as relações entre diferentes formulações do discurso indigenista ${ }^{5}$. No Código Civil, o índio é visto como relativamente incapaz, ou seja, equivalente a um adolescente de dezesseis a dezoito anos. Este, pela constituição, está sujeito à legislação indigenista.

A coexistência de diferentes concepções indigenistas cristalizada nos distintos documentos que constituem a legislação sobre o tema, expressa a heterogeneidade da imagem do índio na consciência nacional.

A possibilidade de práticas estigmatizadoras implicadas na tradução da condição de menoridade como inferioridade, é explicitada pela concepção antropológica, que, ao valorizar a alteridade, leva a enfatizar o direito à diferença. Este, em termos da sua

\footnotetext{
5 Adoto aqui o termo discurso considerando que este, como linguagem, "faz sentido para sujeitos inscritos em estratégias de interlocução, em posições sociais ou em conjunturas históricas” (Mainguenau, 1989:12), com base na definição da escola francesa da análise de discurso (AD). Esta abordagem, criada no âmbito do estruturalismo que implicou interação da linguística com as ciências sociais, tem assumido crescentemente seu caráter interdisciplinar sobretudo no que se refere considerar a historicidade e a materialidade da língua. Embora nascendo no campo estruturalista, a AD aproxima-se da hermenêutica na busca do sentido oculto, que é no entanto captável mediante a aplicação de técnicas analíticas. Entre estas técnicas que dizem respeito às ciências sociais, destaca-se a identificação das repetições e do interdiscurso que é um efeito do pré-construído (Courtine, apud Maingueneau, 1989). Daí deriva a dedução do não dito, pelo trabalho do impensado no pensamento, que considera aqui os sujeitos indígenas e sua deliberada intervenção na política indigenista;
}

RRASILIANA- Journal for Brazilian Studies. Vol. 5, n.2 (July, 2017). ISSN 2245-4373.

(c) (1) ब $\Theta$ 
implementação, implica um estatuto jurídico especial. Ainda está vigente o estatuto do Índio de 1964, em cujo cerne está a instituição da tutela baseada no princípio da "relativa incapacidade" que se mostra insustentável nos marcos do protagonismo indígena (Lacerda, 2007).

Do ponto de vista da luta pela garantia dos direitos territoriais indígenas, a tutela determinada pelo Estatuto do Índio constitui-se uma "ferramenta imperfeita" ${ }^{6}$, ou seja, um instrumento ineficaz uma vez que condiciona a possibilidade de proteção à regulamentação jurídica de práticas tutelares. Nesta concepção, os tutelados têm direitos à proteção contanto que mediada pelo órgão tutor. Mas esta proteção está condicionada à naturalização da ideia que são sujeitos a uma representação de menoridade - ainda que relativa. Formulado dentro de propósitos da política indigenista geradora de incongruências, o Estatuto do Índio prescreve uma classificação segundo "graus de integração" do índio à comunhão nacional ("isolados", "em vias de integração", "integrados"). Os integrados estariam excluídos dos direitos gerados pela legislação especial. Conforme dispositivos desta Lei, grupos e indivíduos podem ser emancipados, de acordo com sua iniciativa, sendo esta emancipação vista como consequência de um processo evolutivo.

À concepção científica de evolução estão associados juízos de valor, como o preconceito embutido na ideia da inevitabilidade da "aculturação" dos índios considerados integrados. Ou seja, os índios integrados perdem sua cultura. Deste modo, cultura "original" é essencializada, como se pudesse ser guardada um recipiente cujo conteúdo seria esvaziado conforme eles cumprissem as etapas de um processo de integração considerado natural. Como se a cultura indígena não fosse transformada desde o primeiro contato, e os índios não tivessem capacidade para reinterpretar formas culturais não autóctones dentro de seus próprios parâmetros. A cultura é vista assim com causa, e não consequência da existência de grupos etnicamente diferenciados.

A própria definição de índio está comprometida quando se parte do critério cultural. Ao contrário, sua definição na Constituição baseia-se ma definição de comunidade indígena em termos da consciência por seus membros de "sua continuidade histórica com sociedades pré-colombianas" (Carneiro da Cunha, 1987:26). Assim, não seriam excluídas as "comunidades integradas", cujos membros seriam "incorporados à comunhão nacional e reconhecidos no pleno exercício de seus direitos civis, ainda que conservem usos e costumes

\footnotetext{
${ }^{6}$ O termo "ferramenta imperfeita" ("Mauvais Outil”) foi cunhado por Paul Henry Paul Henry .. (1992). - no âmbito da Escola Francesa de Análise de Discurso (AD) - para caracterizar as ambiguidades da linguagem. Estamos aqui transpondo o termo para a caracterização do discurso jurídico, que é um campo específico da linguagem.
}

RRASILIANA- Journal for Brazilian Studies. Vol. 5, n.2 (July, 2017). ISSN 2245-4373. 
característicos de sua cultura" (art $4^{\circ}$, III). Volta p fantasma da emaciação quando considerados "emancipados", como "assimilados", ou seja, como "não índios", advoga-se que percam seus direitos especiais garantidos na Constituição.

Com o Estatuto do Índio, foi prescrita a demarcação das áreas indígenas. Esta prescrição não foi atendida no período de dez anos, como estava previsto inicialmente. A definição de figuras jurídicas como posse e propriedade da terra indígena, comporta ambiguidades implicando divergências quanto às interpretações dos direitos territoriais indígenas. (Carneiro da Cunha, 1987:22).

$\mathrm{Na}$ Constituição de 88 a posse indígena é reconhecida com base na ocupação tradicional, mas a propriedade continua sendo da União, cujo interesse público é ressalvado segundo o que dispuser lei complementar. Como no Estado age-se em consonância com interesses contraditórios, os direitos coletivos de cada grupo indígena sobre seu território, cuja continuidade é étnica e historicamente construída de acordo com a ocupação costumeira reconhecida legalmente. Seus direitos, no entanto, são colocados em cheque de acordo com o poder de pressão dos grupos que cobiçam recursos contidos nestes territórios.

Se a nível mais geral o direito na sociedade moderna concebe todos os indivíduos como iguais, as diferenças aparecem na definição de categorias particulares, como os índios, considerados no código civil de 1916 (Lei n 3.071 de 1.1.1916, art 6 , IV como "relativamente incapazes" para exercer certos atos da vida pública, equiparados aos adolescentes (maiores de 16 e menores de 21 anos), e portanto considerados como não adultos. Isto implica a prescrição que sejam submetidos à tutela do Estado, através do organismo indigenista (SPI, FUNAI). A incapacidade absoluta, que os equipararia aos loucos e os surdos-mudos, só não foi incluída no Projeto do Novo Código Civil, em 1983, porque houve manifestação da sociedade civil.

A Constituição de 88 se coloca em um novo patamar ao reconhecer aos índios, suas comunidades e organizações o direitos de "ingressar em juízo em defesa de seus direitos e interesses" como "partes legítimas" (art.232).

Apesar de romper com os pressupostos assimilacionistas e integracionistas, ela se atém ao que dispõe a legislação especial, como regulamentado pelo Estatuto do Índio ainda em vigor, tal proteção é efetivada por meio do exercício do poder tutelar. Três projetos de novo Estatuto do Índio foram engavetados, tanto os dois que previam a compatibilização com o prescrito na Constituição e o terceiro que mantinha a figura da tutela.

A noção remonta à concepção de "tutela orfanológica" do Direito Privado, a qual implica a introjeção pelos índios da imputação de menoridade e os leva à busca proteção 
junto a "patrões", evidenciando vínculos de dependência contraídos com detentores de recursos econômicos. Se o tutor é omisso ou infiel, o tutelado fica sujeito a uma posição frágil, o que pode ter consequências desastrosas em uma sociedade regida pela propriedade privada e pela ideia de acumulação individual como fonte de poder.

As descontinuidades entre as leis enquanto concepções jurídicas e as práticas históricas e o habitus tutelar impedem, contudo de garantir os direitos previstos constitucionalmente. A figura da tutela funciona como um discurso pré-construído entranhado nas formações sociais concretas. Os índios ao reivindicar proteção quando cujas terras continuam sendo ameaçadas apesar de processos demarcatórios, participam do imaginário criado pela política indigenista, pois se apresentam como desprotegidos se se recorrendo a direito previsto na Constituição de 1988, veem que ela remete ao já ultrapassado Estatuto que concebe a tutela como ferramenta de proteção, a esta condicionados pelo habitus indigenista.

Concebida em termos da representação por seus membros de sua continuidade com os povos pré-colombianos, a figura da "comunidade indígena" é referida às práticas concretas, sem o que não passaria de entidade idealizada e utópica. Após os processos demarcatórios, os grupos indígenas frequentemente são forçados pelas condições precárias em que vivem a depender de agentes e agências da sociedade nacional, o que os leva muitas vezes a romper com os grupos de proveniência, ao integrar redes sociais características da sociedade colonizadora, como as redes de clientela, segmentos sociais como o campesinato ou aglomerados vinculados a um "lumpen proletariado" urbano. As associações indígenas são atravessadas por influências muitas vezes contrastantes, e as organizações indígenas nascem em um campo complexo de influências. O pressuposto de que as coletividades indígenas estariam legitimamente representadas por estas organizações e associações não é necessariamente demonstrável em casos específicos. No entanto, a figura das comunidades étnicas é um instrumento eficaz de afirmação destas coletividades, desde que as mesmas construam seus canais de participação e representação, em consonância com sua organização social, costumes e valores próprios a cada povo. Estes canais de participação virtualmente configuram a potencialidade de um diálogo difícil entre diferentes atores, representantes de diferentes interesses, submetidos aos ordenamentos jurídicos da sociedade nacional.

A legislação indigenista é concebida dentro do jogo de relações envolvido pela luta pelo poder jurídico, em uma esfera distinta (embora possam se observar conexões) dos mecanismos capilares de intervenção indigenista, determinados a partir do campo das práticas indigenistas que têm progressivamente sido esvaziadas, uma vez que outros 
ministérios assumem atribuições do trato da sociedade nacional com os índios, através de programas do ministério da Educação e da Saúde, por exemplo. A persistência de relações clientelistas, paternalistas e tutelares dificulta o reconhecimento da agencialidade de organizações indígenas.

\section{$O$ vigor do movimento indígena}

Não pode deixar de ser considerado o excedente de significado que carrega a imagem do índio. Os índios são exaltados na literatura e nos meios de comunicação, mas pouco é feito para modificar as condições desumanas em que vivem nas situações de fronteira. Muitos brasileiros (as) dizem com orgulho que descendem de indígenas, mas esquecem que nas histórias de família verdadeiros tabus escondem em que condições de conflito latente ou manifesto nasceram seus antepassados. No plano da consciência nacional, o indianismo, parece valorizar positivamente a identidade indígena, mas o seu caráter ufanista está imbuído de estereótipos que são expressões da discriminação étnica. Quando se trata das lutas pelos recursos territoriais, os interesses anti-indígenas adquirem positividade, dado o estigma constitutivo da condição de minoria étnica nas áreas de conflito interétnico.

O fato novo, todavia, que se apresenta a partir das últimas décadas do século XX é a emergência das organizações indígenas a nível local e sua articulação em âmbito regional, nacional e internacional. É com elas que os atores sociais e o poder público têm sido postos a negociar. Mas a análise antropológica deve considerar os campos políticos e discursivos no qual estas organizações se constituem enquanto ator virtual.

Em documento dirigido à Presidência da República em 26 de agosto de 20167, a APIB manifesta o entendimento que a Constituição de 1988, ao reconhecer aos sujeitos indígenas o direito de constituir organização representativa, coloca em questão a tutela tal como presumida pelo Estatuto do Índio. No entanto, reivindica a atuação do Estado no sentido de garantir os territórios e a integridade física dos índios. Segundo o Código Civil e a Constituição de 1988 a capacidade do Índio, bem como os mecanismos de sua proteção, devem ser definidos pela legislação especial consubstanciada no ainda vigente Estatuto do índio que continua assim a determinar as práticas tutelares. Evidencia-se a presença neste texto do discurso pré-construído que condiciona a proteção que é reivindicada pelos índios à figura jurídica da tutela, for falta, na legislação especial de instrumento mais eficaz, que

\footnotetext{
${ }^{7}$ URL https://mobilizacaonacionalindigena.wordpress.com/
} 
deveria ser determinado por novo Estatuto do Índio. O fato da permanência do Estatuto do Índio de 1974 - sem que se tenha imposto um consenso de legislação específica para consolidar as inovações da constituição de 1988 - evidencia que nas práticas enunciativas indígenas, em que pese sua heterogeneidade, há demandas não autorizadas pela formação discursiva dominante.

Nos dias de hoje, as terras indígenas estejam ou não demarcadas sofrem todo o tipo de ameaças pelos senhores de terras, especuladores e agentes anti-indígenas que pressionam o Congresso como uma caixa de ressonância de projetos gananciosos. A Proposta de Emenda à Constituição proposta por parlamentares defendendo os interesses dos ruralistas e contrária às atribuições de instâncias do poder executivo no Brasil, arquivada graças à mobilização indígena em 2017 é novamente acionada em nova conjuntura de supressão de direitos de cidadania. Acirram-se as intimidações e ameaças contra estes movimentos, assumindo um caráter anti-indígena. Estes são corporificados nos primeiros meses de 2017 com a ocupação de postos na FUNAI por dirigentes não aceitos pelas organizações indígenas.

A retomada dos interesses em jogo na Comissão Parlamentar de Inquérito que focaliza ações da FUNAI e de antropólogos comprometidos eticamente com as demarcações e a defesa dos direitos dos povos originários. Retiradas as máscaras dos atores indigenistas, coloca-se aqui na posição reflexiva e na busca de diálogo com estudantes indígenas procurando agir de acordo com os ensinamentos da história. Como nos tempos heroicos do SPI, resta aqueles que querem garantir seus territórios partir com os seus próprios recursos para demarcação de suas terras sem alimentar fantasmas do passado ou acreditar na ação protecionista os órgãos criados para defendê-los, mas que têm sido reiteradamente usados para garantir interesses contrários.

\section{Referencias Bibliográficas}

Albert, Bruce, «Territorialité, ethnopolitique et développement: à propos du mouvement indien en Amazonie brésilienne », Cahiers des Amériques latines, n²3, Paris, IHEAL, 1997, p. $177-211$

Barth, Friedrik. 2000. O Guru, o iniciador, e outras variações antropológicas. Rio de Janeiro, Contra Capa,

RRASILIANA- Journal for Brazilian Studies. Vol. 5, n.2 (July, 2017). ISSN 2245-4373. 
Bicalho, Poliene Soares dos Santos 2010: 'PROTAGONISMO INDÍGENA NO BRASIL' Movimento, Cidadania e Direitos (1970-2009) - Brasilia-DF - 2010. Departamento de História

Bornheim, Gerd. 1999. “O sujeito e a norma”. Ética. Org.: Adauto Novaes. São Paulo, Cia. das Letras.

Camacho, Hugo 2003 “Cosmovisão Tikuna” em Magüta Arü Inü. Jogo de Memória. Pensamento Magüta (org). Belém, Museu Goeldi, (pp 53-56)

Cardoso de Oliveira, Roberto. 1972. O índio e o mundo dos brancos. São Paulo, Pioneira . 1988 A crise do indigenismo. Campinas: Editora da UNICAMP. 1991 Razão e afetividade: o pensamento de Lucien Lévy-Bruhl. Campinas, Unicamp.

. 1996 Posfácio. 1994- Trinta Anos Depois. Em O índio e o mundo dos brancos. Campinas, UNICAMP, pp 183-188. 1998 O trabalho de antropólogo. Brasília, Paralelo 15,

Carneiro da Cunha, Manuela . 1987 o Direitos do Indio. Ensaios e documentos. São Paulo, Brasiliense

Cascudo, João de Câmara.1962 Dicionário do Folclore Brasileiro. Rio, Instituto Nacional do Livro.

Dilthey, Wilheim. 1989 Selected Works. Volume I. Introduction to the Human Sciences. Princeton University Press,

Faulhaber, Priscila. 1983. Índios Civilizados. Etnia e Alianças em Tefé. Dissertação de Mestrado. Brasilia, UNB. p.79-106. . 1986 Tentando Uma Antropologia Operativa. ANUARIO ANTROPOLOGICO 85. , . 1987 O Navio Encantado. Etnia e Alianças e Tefé Belém, Museu Goeldi. . 1998 O Lago do Espelhos. Etnografia do Saber sobre a fronteira em TefélAM. Belém, Museu Goeldi/FUNTEC. 
. 2003 Processos Jurídicos, Ação Corporativa e Etnopolítica Tikuna no Brasil Arquivos do Museu Nacional, Rio de Janeiro, v.61, n.2, p.61-70, abr.jun.

. 2005 Identidades contestadas e deslocamentos Miranha na fronteira Brasil-Colômbia In: Nacionalidade e Etnicidade em Fronteiras (Ed: Roberto Cardoso de Oliveira e Stephen Baines.Brasília, Editora Universidade de Brasília, 2005, pp. 241-269

. 2011 A dinâmica Ticuna e as fronteiras. São Paulo, HUCITEC, 104-119.

. 2012 O indigenismo militar do Amazonas como veículo de incorporação dos índios Miranha à nacionalidade In: Memória do SPI.Textos, imagens e documentos sobre o Serviço de Proteção aos Índios (1910-1967) ed.Rio de Janeiro : Museu do Índio,, p. 419-425.

Foucault, Michel. 1962. 1969. “Qu'est-ce qu'un auteur? Dits et écrits. 1954-1988. T.I. 1964-1969. Paris: Gallimard. pp 789-821 . 1966. Les Mots et les choses. Une archéologie des sciences humaines. Paris, Gallimard,

Freire, C. A da Rocha. Indigenismo e Antropologia. O Conselho Nacional de Proteção aos Índios na gestão Rondon. Dissertação de Mestrado. Rio de Janeiro, Museu Nacional, 1990.

. O SPI na Amazônia. Política Indigenista e Conflitos regionais 190-1932. Rio, Museu do Índio, 2007,

Galvão, Eduardo. 1979.Índios e Brancos no Brasil. Encontro de Sociedades. Rio de Janeiro, Paz e Terra.

Garcés, Cláudia Lopéz 2005 A vida do Povo Tikuna na Tríplice Fronteira. Belém, Museu Goeldi.

Geertz, Clifford. 1973. The interpretation of cultures; selected essays. New York: Basic Books. . 1988. Works and lives. The anthropologist as an author. Stanford University Press.

Henry, Paul 1992A Ferramenta Imperfeita. Língua, sujeito e discurso. Campinas, UNICAMP

Lacan, Jacques. 1988 "A excomunhão" - O Seminário. Livro 11. Os quatro conceitos fundamentais da psicanálise. Rio de Janeiro, Zahar.

RRASILIANA- Journal for Brazilian Studies. Vol. 5, n.2 (July, 2017). ISSN 2245-4373. 
Lacerda, Rosane Freire 2007. Diferença não é Incapacidade: Gênese e trajetória histórica da concepção de Incapacidade Indígena e sua insustentabilidade nos marcos do protagonismo dos povos indígenas e do texto constitucional de 1988. Tese de doutorado. Brasília, UNB.

Leach, Edmund. 1989. Political Systems in Highland Burma. London, Athlone

Leenhardt, Maurice. 1949. "Préface”. Les carnets de Lucien Lévy-Bruhl. Paris, PUF, pag. V-XXI.

Lévi-Strauss, Claude. 1962. O pensamento selvagem. São Paulo, Companhia Editora Nacional. . 1981. La Via de las máscaras. Mexico, Siglo Veintiuno.

1991. O Cru e o Cozido. São Paulo, Brasiliense,

Lévy-bruhl, Lucien. 1957. La Mentalidad Primitiva. Buenos Ayres, Leviatan. 1949. Les carnets Paris, PUF. PUF. .1963. La mythologie Primitive. Le monde Mythique des Australiens et des Papous. Paris, Lima, Antonio Carlos de Souza 1995. Um grande cerco de paz: poder tutelar, indianidade e formação do Estado no Brasil. Petrópolis, Vozes.

2012. O exercício da tutela sobre os povos indígenas: considerações para o entendimento das políticas indigenistas no Brasil contemporâneo. Revista de Antropologia, São Paulo, USP, v. 55n² 2, pp 781-832.

Maingueneau, Dominique. 1989 Novas tendências em análise do discurso. Campinas, UNICAMP.

Malinowski, Bronislaw: 1984. "O mito na psicologia primitiva". Magia, Ciência e Religião. Lisboa, Edições 70. Pag 97-153.

Marcus, George and Fisher, Michael. 1986. Anthropology as Cultural Critique. An experimental moment in human sciences. Chicago, University of Chicago Press.

Oliveira, João Pacheco. 1988 "O nosso governo": Os Tikuna e o regime tutelar. São Paulo: Marco Zero; Brasília: MCT/ CNPq. 
. 1999. Ensaios de Antropologia Histórica. Rio, UFRJ, pág. 60-99.

2014. Sem a tutela, uma nova moldura de nação. Rio de Janeiro, e-papers.

. «Stratégies politiques des indigènes dans l'Amazonie brésilienne : agence, échelle et territoire ", Cahiers des Amériques latines [Online], 78 | 2015, posto online no dia 13 Janeiro 2016, consultado o 29 Novembro 2016. URL: http://cal.revues.org/3562 ; DOI : $10.4000 / \mathrm{cal} .3562$

Ramos, Alcida Rita O índio hiper-real. 2000, http://www.anpocs.org.br/portal/publicacoes/rbcs_00_28/rbcs28_01.htm

Redfield, R., Linton, R., Herskovits, M. J. 1936. "Memorandum on the Study of Aculturation". American Anthropologist, XXXVIII, :149-152.

Ribeiro Darcy, Os Índios e a civilização, Rio de Janeiro, Civilização Brasileira, 1970.

Ricoeur, Paul. 1977. Da Interpretação. Ensaio sobre Freud. Rio de Janeiro, Imago . 1986. Du texte à L'Action. Essais d'herméneutique, II. Paris, Eprit/Seuil.

Spiro, Melford. 1992. "Cultural relavism and the future of anthropology". Rereading Cultural Anthropology (Ed.: Georg Marcus). Duhan and London, Duke University.

Stocking, George. 1996. Volksgeist as method and ethic. Essays on Boasian Ethnography and the German Anthropological Tradition. History of Anthropology vol 8. The University of Wisconsin Press.

RRASILIANA- Journal for Brazilian Studies. Vol. 5, n.2 (July, 2017). ISSN 2245-4373. 